\title{
Effects of sex, tobacco smoking, and alcohol consumption osteoporosis development: Evidence from Taiwan biobank participants
}

\author{
Chung-Yuan Yang ${ }^{1}$, Jerry Cheng-Yen Lai ${ }^{2,3}$, Wei-Lun Huang ${ }^{3,4}$, Chiao-Lin Hsu ${ }^{5,6}$, Shaw-Ji Chen ${ }^{1,3,7}$
}

\begin{abstract}
INTRODUCTION Osteoporosis is major public health concern, but the long-term impacts of tobacco and alcohol consumption on its development are unclear. This study analyzed the relationship between tobacco and alcohol use and osteoporosis by using data from the Taiwan Biobank (TWB), established in 2012.

METHods Participants in TWB were included in our study, with a total of 18394 respondents included for analysis. To investigate the relationship between tobacco and alcohol use and osteoporosis, we surveyed their bone mineral density (BMD), consumption of tobacco and alcohol and other covariate data.

RESULTS We found that participants in the tobacco smoking only group $(\mathrm{OR}=1.24$; 95\% CI: $1.08-1.42, \mathrm{p}=0.003)$ and the group that both smoked and consumed alcohol $(\mathrm{OR}=1.39 ; 95 \% \mathrm{CI}: 1.09-1.77, \mathrm{p}=0.008)$ were more likely to develop osteoporosis than were participants who neither drank alcohol nor smoked. Menopause is strongly associated with osteoporosis in women, and we found that women who used alcohol or tobacco were not at a significantly higher risk than those in the reference group (tobacco only, OR=1.15; 95\% CI: 0.86-1.53, $\mathrm{p}=0.345$; both tobacco and alcohol, OR=0.61; 95\% CI: 0.14-2.60, p=0.5040). However, men in these groups were at a significantly higher risk than the reference group (tobacco only, OR=1.26; 95\% CI: 1.07-1.48, $\mathrm{p}=0.006$; both tobacco and alcohol, $\mathrm{OR}=1.32$; 95\% CI: $1.03-1.70, \mathrm{p}=0.030)$. Menopause was a significant risk factor for osteoporosis $(\mathrm{OR}=2.46$; 95\% CI: $1.77-3.41, \mathrm{p}<0.001)$.

CONCLUSIONS The influence of tobacco use on osteoporosis was significant, particularly in men, but the effects of alcohol consumption were equivocal in our study. The interactions between tobacco use, alcohol use, and menopausal status on osteoporosis should be considered in future studies.
\end{abstract}

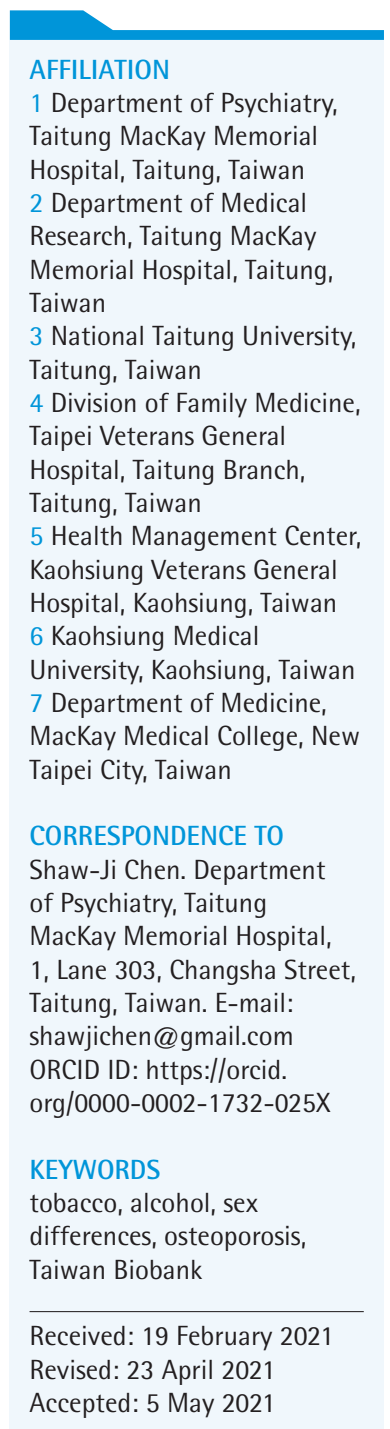

\section{INTRODUCTION}

Osteoporosis is an important risk factor affecting public health. Osteoporosis begins without major discomfort but leads to age-related fractures later in life $\mathrm{e}^{1}$. Osteoporosis is a reduction in bone mineral density (BMD). Usually, it is asymptomatic and is therefore undetected until a fracture ${ }^{2}$. In people with osteoporosis, their bone tissue is qualitatively 
normal but their BMD is quantitatively reduced ${ }^{3}$. People with osteoporosis have a BMD lower than the average BMD of healthy adults of the sex and age group by 2.5 standard deviations (SD: T-score $\leq$ $-2.5)^{4}$. The occurrence of osteoporosis is increasing in older adults, especially postmenopausal older women ${ }^{5}$. Osteoporosis is also a frequent cause of bone fractures. The commonest fracture sites among older adults are the hip, spine, and forearm, and such fractures have other osteoporosis-related effects (e.g. hospitalization, illness, and increased healthcare costs $)^{6}$.

Complex interactions between genetic and environmental factors have been reported to contribute to the pathophysiology of osteoporosis ${ }^{7-9}$. These factors include tobacco smoking, alcohol consumption, low physical activity, weight change, nutrition intake and absorption (specifically, calcium and vitamin D), fracture history, corticosteroid use, hormonal factors, genetic factors, and female sex ${ }^{9,10}$.

Certain factors contributing to osteoporosis, such as sex and genetics, are not modifiable, but tobacco and alcohol use can be altered. However, the effects of tobacco and alcohol use on the development of osteoporosis are not well understood. Possible mechanisms of the effect of tobacco smoking on bone health remain unclear, and some findings are controversial ${ }^{11}$. Research indicates that tobacco smoking may cause an imbalance in the process of bone turnover, leading to lower bone mass and BMD, thus increasing susceptibility to osteoporosis ${ }^{12}$. Alcohol consumption is also associated with an increased incidence of fractures and complications ${ }^{13}$. However, the details of the complex effects of alcohol on bone tissue are not well understood. One study indicated that menopausal women who resumed alcohol use had reduced bone turnover markers ${ }^{14}$. Therefore, further research into the long-term effects of tobacco and alcohol consumption on osteoporosis is recommended.

In Taiwan, owing to its well-established healthcare system, life expectancy and therefore the proportion of older adults has been increasing. The 2005-2008 National Nutrition and Health Survey in Taiwan (NAHSIT) investigated the prevalence of osteoporosis by measuring BMD, and it was discovered that the prevalence of osteoporosis had increased since the 1999-2000 NAHSIT ${ }^{15,16}$. Tobacco smoking and alcohol consumption also increased in prevalence after 2000, when Taiwan became a member of WTO. Therefore, clarifying the effects of tobacco and alcohol consumption on osteoporosis is critical.

The aim of this study was to explore the influence of tobacco smoking and alcohol consumption on the development of osteoporosis. Data collected in the Taiwan Biobank (TWB) since 2012 could be used to identify possible interactions among tobacco smoking, alcohol consumption, and osteoporosis.

\section{METHODS}

\section{The Taiwan Biobank (TWB)}

The TWB is sponsored by the Taiwanese Government. Its purpose is to collect lifestyle and genetic data from Taiwanese people ${ }^{17,18}$. TWB is a populationbased dataset, which aims to recruit 200000 community-based healthy participants aged 30-70 years without history of cancer before 2024. In 2020, 29 recruitment centers contributed information on 105387 volunteering participants to the TWB. In addition to blood samples and physical examination, each participant completed a structured questionnaire on personal information and lifestyle factors through face-to-face interviews with a TWB researcher.

\section{BMD measurement}

Broadband ultrasound attenuation (BUA) with highspeed quantitative ultrasound measurement was used to measure BMD by the TWB ${ }^{13,19}$. BUA is easy to administer and is therefore suitable for TWB data collection.

\section{Alcohol consumption and tobacco smoking}

Alcohol consumption among participants was categorized by defining alcohol consumers as those with a weekly intake of over $150 \mathrm{cc}$ of alcohol for at least 6 months at the time of BMD measurement. Tobacco smoking was also surveyed in this study. Tobacco smokers were those who had smoked regularly for at least 6 months by the time of their BMD measurement.

\section{Covariates}

Covariate data were also collected (sex, age, body mass index [BMI], regularity of exercise, educational level, family history of osteoporosis, and diabetes mellitus [DM] status) for statistical analysis in accordance with previous studies ${ }^{20-22}$. In particular, gathering 
data on menopause was important in women, so only female participants aged $\geq 40$ years were enrolled in the study. The demographic data were collected during the TWB enrollment interview. For the TWB, the body height and weight of each participant were measured, and BMI was calculated as weight $(\mathrm{kg}) /$ (height in $\mathrm{m})^{2}$.

\section{Statistical analysis}

The characteristics between participants with different alcohol drinking and tobacco smoking behaviors were described by means and standard deviations for continuous and percentages for categorical data. Tea and drinking behaviors of participants were classified into one of four categories: no drinking and no smoking, only smoking but no drinking, only drinking but no smoking, or both drinking and smoking. All variables in the different groups were compared using one-way analysis of variance (ANOVA) for continuous data, and $\chi^{2}$ or Fisher's exact tests for categorical data. Multivariable logistic regression was performed to estimate the adjusted odds ratios (AOR) for the risk of osteoporosis in men and women with tea and alcohol drinking behaviors, with adjustment for baseline demographic characteristics and lifestyle behavior. To account for gender as potential interaction associated with tea and drinking behaviors, separate multivariate logistic models were estimated for male and female participants. Independent variables included for adjustment in the multivariable logistic model was guided by the results from participant characteristics with $\mathrm{p}<0.05$. All data transformations and statistical analyses were conducted by the SAS statistical software for Windows (Version 9.4; SAS Institute, Cary, NC, USA). The null hypothesis was rejected at an alpha level of 0.05 .

\section{RESULTS}

\section{Basic characteristics of TWB participants}

After the exclusion of respondents aged $<40$ years $(n=3819)$ and those with incomplete or missing information on independent variables of interest $(n=189), 18394$ participants were included for analysis. All details including sex, age, BMI, regular exercise, educational level, and DM are given in Table 1.

All participants were classified into four groups according to their smoking and drinking status, including: 'neither alcohol nor tobacco' $(\mathrm{n}=13733$; $74.7 \%)$; 'tobacco but not alcohol' ( $\mathrm{n}=3621 ; 19.7 \%)$, 'alcohol but not tobacco' ( $\mathrm{n}=272 ; 1.5 \%)$, 'both alcohol and tobacco' $(\mathrm{n}=768 ; 4.2 \%)$; the average ages (SD) were, respectively, 54.8 (7.7), 54.5 (7.9), 53.8 (8.0), and 53.4 (7.7) years in the four groups (Table 1$)$. The numbers and percentages of men were 2529 (18.4\%), $2962(81.8 \%), 153(56.3 \%)$, and $726(94.5 \%)$ in the four groups, respectively. The numbers and percentages of participants living in rural areas were $833(6.1 \%), 258(7.1 \%), 23(8.5 \%)$ and $75(9.8 \%)$ in the four groups, respectively. The numbers and percentages of participants with a college degree were 8205 (59.7\%), 1901 (52.5\%), 168 (61.8\%), and $456(59.4 \%)$ in the four groups, respectively. The numbers and percentages of participants with DM were 790 (5.8\%), 300 (8.3\%), 13 (4.8\%), and $56(7.3 \%)$ in the four groups, respectively. The numbers and percentages of participants with a BMI $\geq 25$ were 4398 (32.0\%), 1683 (46.5\%), $112(41.2 \%)$, and $419(54.6 \%)$ in the four groups, respectively. The numbers and percentages of participants who exercised regularly were $7202(52.4 \%), 1733$ $(47.9 \%), 154(56.6 \%)$, and $374(48.7 \%)$ in the four groups, respectively. These covariates were all $(p<0.001)$ significantly different between the four groups (Table 1).

\section{Influence of tobacco and alcohol on osteoporosis}

Participants who did no use alcohol or tobacco were the reference group and were compared with participants in the other three groups. A T-score of $\leq 2.5$ for BMD was considered to indicate osteoporosis. We selected all variables that were determined to be significant $(\mathrm{p}<0.05)$ during the univariate analysis as covariates in the logistic regression analysis. Participants who smoked only or used both tobacco and alcohol were more likely to have osteoporosis compared with the reference group $(\mathrm{AOR}=1.24 ; 95 \%$ CI: $1.08-1.42$ and AOR=1.39; 95\% CI: 1.09-1.77; respectively). Participants were less likely to have osteoporosis in other categories, such as those who had a college degree (AOR $=0.86$; 95\% CI: 0.78-0.96), who had DM (AOR=0.78; 95\% CI: 0.65-0.93), who had a BMI of $<25$ (AOR=0.70; 95\% CI: 0.64-0.78), and who regularly exercised $(\mathrm{AOR}=0.84 ; 95 \% \mathrm{CI}$ : 0.77-0.92) (Table 2). 
Table 1. Baseline characteristics of total participants stratified by alcohol and tobacco consumption behaviors in Taiwanese men and women aged 40-70 years (2008-2015) ( $\mathrm{N}=18394)$

\begin{tabular}{|c|c|c|c|c|c|}
\hline \multirow[t]{2}{*}{ Characteristics } & $\begin{array}{c}\text { Neither alcohol nor } \\
\text { tobacco } \\
(\mathrm{N}=13733 ; 74.7 \%)\end{array}$ & $\begin{array}{c}\text { Tobacco but not } \\
\text { alcohol } \\
(\mathrm{N}=3621 ; 19.7 \%)\end{array}$ & $\begin{array}{c}\text { Alcohol but not } \\
\text { tobacco } \\
(\mathrm{N}=272 ; 1.5 \%)\end{array}$ & $\begin{array}{c}\text { Both alcohol and } \\
\text { tobacco } \\
(\mathrm{N}=768 ; 4.2 \%)\end{array}$ & \\
\hline & $n(\%)$ & $n(\%)$ & $n(\%)$ & $n(\%)$ & $p$ \\
\hline Age (years), mean $\pm S D$ & $54.8 \pm 7.7$ & $54.5 \pm 7.9$ & $53.8 \pm 8.0$ & $53.4 \pm 7.7$ & $<0.001^{* * *}$ \\
\hline Male & 2529 (18.4) & $2962(81.8)$ & $153(56.3)$ & $726(94.5)$ & $<0.001^{* * *}$ \\
\hline \multicolumn{6}{|l|}{ Residential area } \\
\hline Rural & $833(6.1)$ & $258(7.1)$ & $23(8.5)$ & $75(9.8)$ & $<0.001^{* * *}$ \\
\hline Non-Rural & 12900 (93.9) & 3363 (92.9) & $249(91.5)$ & $693(90.2)$ & \\
\hline \multicolumn{6}{|l|}{ Education level } \\
\hline College or graduate school & 8205 (59.7) & $1901(52.5)$ & $168(61.8)$ & $456(59.4)$ & $<0.001^{* * *}$ \\
\hline $\begin{array}{l}\text { High school, elementary school, or } \\
\text { less }\end{array}$ & $5528(40.3)$ & $1720(47.5)$ & $104(38.2)$ & $312(40.6)$ & \\
\hline \multicolumn{6}{|l|}{ Baseline comorbidity } \\
\hline Family history of osteoporosis & $2092(15.2)$ & $537(14.8)$ & $45(16.5)$ & $109(14.2)$ & 0.725 \\
\hline Diabetes mellitus & $790(5.8)$ & $300(8.3)$ & $13(4.8)$ & $56(7.3)$ & $<0.001^{* * *}$ \\
\hline $\mathrm{BMI}$, mean $\pm \mathrm{SD}$ & $23.8 \pm 3.4$ & $25.0 \pm 3.4$ & $24.6 \pm 3.3$ & $25.4 \pm 3.2$ & $<0.001^{* * *}$ \\
\hline \multicolumn{6}{|l|}{ BMI $\left(\mathrm{kg} / \mathrm{m}^{2}\right)$} \\
\hline$<25$ & $9335(68.0)$ & $1938(53.5)$ & $160(58.8)$ & $349(45.4)$ & $<0.001^{* * *}$ \\
\hline$\geq 25$ & $4398(32.0)$ & $1683(46.5)$ & $112(41.2)$ & $419(54.6)$ & \\
\hline \multicolumn{6}{|l|}{ BMD profile } \\
\hline T-Score, mean \pm SD & $-0.6 \pm 1.6$ & $-0.9 \pm 1.5$ & $-0.5 \pm 1.6$ & $-0.9 \pm 1.4$ & $<0.001^{* * *}$ \\
\hline \multicolumn{6}{|l|}{ T-score $\leq-2.5$ (Outcome) } \\
\hline No & 11955 (87.1) & 3157 (87.2) & $241(88.6)$ & $658(85.7)$ & 0.588 \\
\hline Yes & 1778 (12.9) & $464(12.8)$ & $31(11.4)$ & 110 (14.3) & \\
\hline \multicolumn{6}{|l|}{ Behavioral factors } \\
\hline Regular exercise & $7202(52.4)$ & $1733(47.9)$ & $154(56.6)$ & $374(48.7)$ & $<0.001^{* * *}$ \\
\hline
\end{tabular}

\section{Influence of sex, tobacco use, and alcohol consumption on osteoporosis}

We also investigated the differences in the effects of alcohol consumption and tobacco smoking in women and men by performing a subgroup analysis. Due to the possible influence of menopause on osteoporosis in women, we included menopause as a covariate in the logistic regression analysis. The risk of osteoporosis in men was still significant in those who only smoked $(\mathrm{AOR}=1.26$; 95\% CI: 1.07-1.48) and those who used both alcohol and smoked (AOR=1.32; 95\% CI: 1.031.70). Women did not have a significantly higher risk of osteoporosis if they only smoked (AOR $=1.15 ; 95 \%$ CI: 0.86-1.53) or if they used both alcohol and smoked (AOR=0.61; 95\% CI: 0.14-2.60). Menopause was a risk factor for osteoporosis (AOR=2.46; 95\% CI: 1.77-3.41). Age was the only risk factor across women and men $(\mathrm{AOR}=1.10 ; 95 \%$ CI: $1.09-1.11$ and $\mathrm{AOR}=1.04 ; 95 \%$ CI: 1.03-1.05, respectively). Two protective factors identified were a BMI of $<25$ for both women and men (AOR $=0.59$; 95\% CI: $0.52-0.68$ and AOR $=0.81$; 95\% CI: $0.70-0.93$, respectively) and regular exercise for both women and men (AOR $=0.75$; 95\% CI: $0.66-0.85$ and AOR $=0.80$; 95\% CI: 0.69-0.94, respectively). Women with a college degree had a lower risk of osteoporosis but men with a college degree did not $(\mathrm{AOR}=0.86$; 95\% CI: $0.75-0.98$ and AOR=0.91; 95\% CI: 0.78-1.06, respectively). The influence of $\mathrm{DM}$ in different genders was equivocal $(\mathrm{AOR}=0.86 ; 95 \% \mathrm{CI}: 0.75-0.98$ and AOR $=0.91$; 95\% CI: 0.78-1.06, respectively) (Table 3). 
Table 2. The effect of alcohol and tobacco consumption behaviors on the risk of osteoporosis in Taiwanese men and women aged 40-70 years (2008-2015)

\begin{tabular}{|c|c|c|}
\hline Independent variables & AOR $(95 \%$ CI $)$ & $p$ \\
\hline \multicolumn{3}{|l|}{$\begin{array}{l}\text { Drinking and smoking behavior } \\
\text { (vs neither alcohol nor tobacco) }\end{array}$} \\
\hline Tobacco but not alcohol & $1.24(1.08-1.42)$ & $0.003^{* *}$ \\
\hline Alcohol but not tobacco & $1.04(0.69-1.56)$ & 0.854 \\
\hline Both alcohol and tobacco & $1.39(1.09-1.77)$ & $0.008^{* *}$ \\
\hline Age (years) & $1.08(1.08-1.09)$ & $<0.001^{* * *}$ \\
\hline Female (vs male) & $0.90(0.80-1.03)$ & 0.120 \\
\hline $\begin{array}{l}\text { Residential area (rural vs non- } \\
\text { rural) }\end{array}$ & $1.05(0.86-1.29)$ & 0.603 \\
\hline \multicolumn{3}{|l|}{$\begin{array}{l}\text { Education level (vs none or } \\
\text { elementary school, high school) }\end{array}$} \\
\hline College or graduate school & $0.86(0.78-0.96)$ & $0.005^{* *}$ \\
\hline \multicolumn{3}{|l|}{ Baseline comorbidity } \\
\hline Diabetes mellitus (vs no) & $0.74(0.61-0.89)$ & $0.002^{* *}$ \\
\hline BMI (vs BMI <25) & $0.70(0.63-0.78)$ & $<0.001^{* * *}$ \\
\hline \multicolumn{3}{|l|}{ Behavioral factors } \\
\hline Regular exercise (vs no) & $0.78(0.71-0.86)$ & $<0.001^{* * *}$ \\
\hline
\end{tabular}

\section{Analysis of the alcohol only group}

The osteoporosis risk in the alcohol consumption only group was not significantly higher than in the reference group; however, subgroups of women and men had significantly higher and lower risks of osteoporosis, respectively. We found an AOR of 1.04 (95\% CI: 0.69-1.56) for this group, but within the subgroup of women $(\mathrm{AOR}=1.38$; 95\% CI: 0.77-2.47) and men $(\mathrm{AOR}=0.84 ; 95 \% \mathrm{CI}: 0.47-1.47)$ significant differences were observed. The percentages of women $(43.8 \%)$ and men $(56.3 \%)$ were almost equal in the alcohol consumption only group, and the overall percentage of men was higher than that in the nondrinking and non-smoking group (18.4\%) but lower than that in the smoking-only group $(81.8 \%)$ and in the both smoking and drinking group (94.5\%). The baseline characteristics of the alcohol consumption only group stratified by sex are shown in Table 4 . The percentage of women with a college degree (77.3\%) was significantly higher than the percentage of men $(49.7 \%)$ in this group $(\mathrm{p}<0.001)$ The percentages of men with a family history of osteoporosis, DM, or a BMI $>25(20.9 \%, 7.2 \%$, and $52.3 \%$, respectively) were also significantly higher than those of women

Table 3. Effects of alcohol consumption and tobacco smoking on the risk of developing osteoporosis in men and women aged 40-70 years (2008-2015)

\begin{tabular}{|c|c|c|c|c|}
\hline \multirow[t]{2}{*}{ Independent variables } & \multicolumn{2}{|c|}{ Male } & \multicolumn{2}{|c|}{ Female } \\
\hline & AOR $(95 \%$ CI $)$ & $p$ & AOR $(95 \%$ CI $)$ & $p$ \\
\hline \multicolumn{5}{|c|}{$\begin{array}{l}\text { Drinking and smoking behavior (vs neither } \\
\text { alcohol nor tobacco) }\end{array}$} \\
\hline Tobacco but not alcohol & $1.26(1.07-1.48)$ & $0.006^{* *}$ & $1.15(0.86-1.53)$ & 0.345 \\
\hline Alcohol but not tobacco & $0.84(0.47-1.47)$ & 0.537 & $1.38(0.77-2.47)$ & 0.277 \\
\hline Both alcohol and tobacco & $1.32(1.03-1.70)$ & $0.030^{*}$ & $0.61(0.14-2.60)$ & 0.504 \\
\hline Age (years) & $1.04(1.03-1.05)$ & $<0.001^{* * *}$ & $1.10(1.09-1.11)$ & $<0.001^{* * *}$ \\
\hline \multicolumn{5}{|l|}{ Menopausal status (vs pre-menopausal) } \\
\hline Post-menopausal & & & $2.46(1.77-3.41)$ & $<0.001^{* * *}$ \\
\hline Residential area (rural vs non-rural) & $1.10(0.82-1.47)$ & 0.529 & $0.99(0.75-1.31)$ & 0.950 \\
\hline \multicolumn{5}{|c|}{$\begin{array}{l}\text { Education level (vs none or elementary school, } \\
\text { high school) }\end{array}$} \\
\hline College or graduate school & $0.91(0.78-1.06)$ & 0.221 & $0.86(0.75-0.98)$ & $0.025^{*}$ \\
\hline \multicolumn{5}{|l|}{ Baseline comorbidity } \\
\hline Diabetes mellitus (vs no) & $0.69(0.52-0.92)$ & $0.012^{*}$ & $0.82(0.63-1.06)$ & 0.124 \\
\hline BMI (vs BMI <25) & $0.81(0.69-0.94)$ & $0.006^{* *}$ & $0.58(0.51-0.67)$ & $<0.001^{* * *}$ \\
\hline \multicolumn{5}{|l|}{ Behavioral factors } \\
\hline Regular exercise (vs no) & $0.80(0.69-0.94)$ & $0.007^{* *}$ & $0.75(0.66-0.85)$ & $<0.001^{* * *}$ \\
\hline
\end{tabular}

BMI: body mass index $\left(\mathrm{kg} / \mathrm{m}^{2}\right)$. Cl: confidence interval. AOR: adjusted odds ratio. 
Table 4. Baseline characteristics of men and women who consumed alcohol but did not smoke aged 40-70 years (2008-2015) $(\mathrm{N}=272)$

\begin{tabular}{|c|c|c|c|}
\hline Independent variables & $\begin{array}{c}\text { Male } \\
(n=153 ; \\
56.3 \%) \\
n(\%)\end{array}$ & $\begin{array}{c}\text { Female } \\
(n=119 ; \\
43.8 \%) \\
n(\%)\end{array}$ & $p$ \\
\hline Age (years), mean \pm SD & $54.5 \pm 8.4$ & $52.7 \pm 7.3$ & 0.063 \\
\hline \multicolumn{4}{|l|}{ Residential area } \\
\hline Rural & $15(9.8)$ & $8(6.7)$ & 0.365 \\
\hline Non-Rural & $138(90.2)$ & $111(93.3)$ & \\
\hline \multicolumn{4}{|l|}{ Education level } \\
\hline College or graduate school & $76(49.7)$ & $92(77.3)$ & $<0.001^{* * *}$ \\
\hline $\begin{array}{l}\text { High school, elementary } \\
\text { school, or less }\end{array}$ & $77(50.3)$ & $27(22.7)$ & \\
\hline \multicolumn{4}{|l|}{ Baseline comorbidity } \\
\hline Family history of osteoporosis & $32(20.9)$ & $13(10.9)$ & $0.028^{*}$ \\
\hline Diabetes mellitus & $11(7.2)$ & $2(1.7)$ & $0.035^{*}$ \\
\hline $\mathrm{BMI}$, mean $\pm \mathrm{SD}$ & $25.5 \pm 3.0$ & $23.5 \pm 3.3$ & $<0.001^{* * *}$ \\
\hline \multicolumn{4}{|l|}{ BMI } \\
\hline$<25$ & $73(47.7)$ & $87(73.1)$ & $<0.001^{* * *}$ \\
\hline$\geq 25$ & $80(52.3)$ & $32(26.9)$ & \\
\hline
\end{tabular}

\section{BMD profile}

\begin{tabular}{lrrr} 
T-Score, mean \pm SD & $-0.7 \pm 1.4$ & $-0.4 \pm 1.7$ & 0.168 \\
\hline T-score $\leq-2.5$ (Outcome) & & & \\
\hline No & $135(88.2)$ & $106(89.1)$ & 0.829 \\
Yes & $18(11.8)$ & $13(10.9)$ &
\end{tabular}

Behavioral factors

$\begin{array}{llll}\text { Regular exercise } & 86(56.2) & 68(57.1) & 0.878\end{array}$

BMI: body mass index $\left(\mathrm{kg} / \mathrm{m}^{2}\right)$. SD: standard deviation. BMD: bone mineral density. ${ }^{* * *} p<0.001 ; \chi^{2}$ test or two-sample t-test.

with these conditions $(10.9 \%, 1.7 \%$, and $26.9 \%$, respectively) in this group.

\section{DISCUSSION}

We investigated the influence of tobacco smoking and alcohol consumption on the development of osteoporosis by analyzing the data collected by the TWB because these influences were unclear in previous research $^{23-26}$.

First, we found the participants in the smokingonly group and both smoking and drinking group to be at a higher risk of developing osteoporosis than those in the non-smoking and non-drinking groups. This finding is important for confirming the risk of tobacco smoking in developing osteoporosis, and it is statistically powerful due to the large sample size provided by the TWB. Second, we separated men and women for further analysis because menopause is strongly associated with osteoporosis in women ${ }^{27}$. We found that men who smoked, regardless of alcohol consumption status, had a significantly higher risk of developing osteoporosis than the reference group, although no such risk was found among women with the same characteristics. Therefore, analyses of the influence of tobacco and alcohol on osteoporosis should be performed for participants grouped by sex.

Third, covariates other than tobacco and alcohol consumption were used to adjust the statistical analysis. Covariates such as regular exercise and a BMI $>25$ were determined to be protective factors in our study, in agreement with previous studies ${ }^{28,29}$. Age, another covariate in our study, was also determined to be a risk factor for osteoporosis, as in previous research ${ }^{30}$. However, DM was not correlated with a reduced risk of developing osteoporosis in our study, a finding inconsistent with those of some previous studies $^{31,32}$. To investigate this inconsistency, we separated TWB enrollees into subgroups of men and women and performed an additional analysis. DM significantly increased the risk of developing osteoporosis in men but not in women; this constitutes additional evidence of sex differences in osteoporosis development.

The most significant difference between middleaged men and women was menopause. Menopause was the most significant co-existing risk factor for osteoporosis in our study. Osteoporosis after menopause with the loss of ovarian function and estrogen deficiency is a complex process involving numerous pathways and cytokines in the regulation of osteoclastogenesis ${ }^{33}$.

Postmenopausal osteoporosis might be prevented by adequate estrogen supplementation. The confounding effect of menopause status could explain why the effects of tobacco smoking and alcohol consumption on osteoporosis risk were non-significant in women.

\section{Limitations}

Our study had limitations. First, this study was crosssectional; a longitudinal study might be more effective in evaluating the influences of tobacco and alcohol on osteoporosis over time. Second, daily consumption of 
tobacco and alcohol were not easy to calculate in the study due to the design of the TWB questionnaire. Further cohort studies could better assess the longterm effects of alcohol and tobacco use, particularly if quantitative data on daily alcohol and tobacco use are collected as part of the study protocol.

\section{CONCLUSIONS}

The influence of tobacco use on osteoporosis development was significant, but the effects of alcohol use were unclear. Specifically, men who use tobacco are at a higher risk of osteoporosis development. However, menopausal status was also a major risk factor for osteoporosis development in women. The interactions between tobacco, alcohol, and menopause on osteoporosis should be considered in the further studies.

\section{REFERENCES}

1. Chen FP, Huang TS, Fu TS, Sun CC, Chao AS, Tsai TL. Secular trends in incidence of osteoporosis in Taiwan: A nationwide population-based study. Biomed J. 2018;41(5):314-320. doi:10.1016/j.bj.2018.08.001

2. Saad F, Lipton A, Cook R, Chen YM, Smith M, Coleman R. Pathologic fractures correlate with reduced survival in patients with malignant bone disease. Cancer. 2007;110(8):1860-1867. doi:10.1002/cncr.22991

3. Bartl R, Frisch B. Definition of Osteoporosis. In: Osteoporosis: Diagnosis, Prevention, Therapy. A Practical Guide for all Physicians. From pediatrics to geriatrics. Springer; 2004:24-32. doi:10.1007/978-3-662-09163-0_3

4. Chen YT, Miller PD, Barrett-Connor E, Weiss TW, Sajjan SG, Siris ES. An approach for identifying postmenopausal women age 50-64 years at increased short-term risk for osteoporotic fracture. Osteoporos Int. 2007;18(9):12871296. doi:10.1007/s00198-007-0380-6

5. Woolf AD, Pfleger B. Burden of major musculoskeletal conditions. Bull World Health Organ. 2003;81(9):646656. Accessed February 2, 2021. https://www.ncbi.nlm. nih.gov/pmc/articles/PMC2572542/pdf/14710506.pdf

6. Cummings SR, Melton LJ. Epidemiology and outcomes of osteoporotic fractures. Lancet. 2002;359(9319):17611767. doi:10.1016/S0140-6736(02)08657-9

7. Rizzoli R, Bonjour JP, Ferrari SL. Osteoporosis, genetics and hormones. J Mol Endocrinol. 2001;26(2):79-94. doi:10.1677/jme.0.0260079

8. Gennari L, Becherini L, Falchetti A, Masi L, Massart F, Brandi ML. Genetics of osteoporosis: role of steroid hormone receptor gene polymorphisms. J Steroid Biochem Mol Biol. 2002;81(1):1-24. doi:10.1016/s0960-0760(02)00043-2

9. Aslam H, Holloway-Kew KL, Mohebbi M, Jacka FN, Pasco JA. Association between dairy intake and fracture in an Australian-based cohort of women: a prospective study. BMJ Open. 2019;9:e031594. doi:10.1136/bmjopen-2019-031594

10. Doosti-Irani A, Ghafari M, Cheraghi Z. The High Prevalence of Osteoporosis as a Preventable Disease: The Need for Greater Attention to Prevention Programs in Iran. Iran J Public Health. 2018;47(8):1220-1221. Accessed February 2, 2021. https://ijph.tums.ac.ir/index. php/ijph/article/view/14314

11. Cusano NE. Skeletal Effects of Smoking. Curr Osteoporos Rep. 2015;13(5):302-309. doi:10.1007/s11914-015-0278-8

12. Al-Bashaireh AM, Haddad LG, Weaver M, Chengguo X, Kelly DL, Yoon S. The Effect of Tobacco Smoking on Bone Mass: An Overview of Pathophysiologic Mechanisms. J Osteoporos. 2018;2018:1206235. doi:10.1155/2018/1206235

13. Abukhadir SS, Mohamed N, Mohamed N. Pathogenesis of alcohol-induced osteoporosis and its treatment: a review. Curr Drug Targets. 2013;14(13):1601-1610. doi:10.2174/13894501113146660231

14. Marrone JA, Maddalozzo GF, Branscum AJ, et al. Moderate alcohol intake lowers biochemical markers of bone turnover in postmenopausal women. Menopause. 2012;19(9):974979. doi:10.1097/GME.0b013e31824ac071

15. Lin YC, Pan WH. Bone mineral density in adults in Taiwan: results of the Nutrition and Health Survey in Taiwan 2005-2008 (NAHSIT 2005-2008). Asia Pac J Clin Nutr. 2011;20(2):283-291. Accessed February 2, 2021. http://apjcn.nhri.org.tw/server/APJCN/20/2/283.pdf

16. Wu SJ, Pan WH, Yeh NH, Chang HY. Trends in nutrient and dietary intake among adults and the elderly: from NAHSIT 1993-1996 to 2005-2008. Asia Pac J Clin Nutr. 2011;20(2):251-265. Accessed February 2, 2021. http:// apjcn.nhri.org.tw/server/APJCN/20/2/251.pdf

17. Fan CT, Hung TH, Yeh CK. Taiwan Regulation of Biobanks. J Law Med Ethics. 2015;43(4):816-826. doi:10.1111/jlme.12322

18. Chen CH, Yang JH, Chiang CWK, et al. Population structure of Han Chinese in the modern Taiwanese population based on 10,000 participants in the Taiwan Biobank project. Hum Mol Genet. 2016;25(24):53215331. doi:10.1093/hmg/ddw346

19. Knapp KM. Quantitative ultrasound and bone health. Salud Publica Mex. 2009;51 Suppl 1:S18-S24. doi:10.1590/s0036-36342009000700005

20. Watts NB. The Fracture Risk Assessment Tool (FRAX ${ }^{\circledR)}$ ): applications in clinical practice. J Womens Health (Larchmt). 2011;20(4):525-531. doi:10.1089/jwh.2010.2294

21. Wongdee K, Charoenphandhu N. Osteoporosis in diabetes mellitus: Possible cellular and molecular mechanisms. World J Diabetes. 2011;2(3):41-48. doi:10.4239/wjd.v2.i3.41

22. Matsuzaki M, Pant R, Kulkarni B, Kinra S. Comparison of Bone Mineral Density between Urban and Rural Areas: Systematic Review and Meta-Analysis. PLoS One. 2015;10(7):e0132239. doi:10.1371/journal.pone.0132239 
23. Zhang J, Chen F, Yun F, Chen J. Low level nicotine: a novel approach to reduce osteoporosis incidence. Med Hypotheses. 2010;74(6):1067-1068. doi:10.1016/j.mehy.2009.12.024

24. Gaddini GW, Turner RT, Grant KA, Iwaniec UT. Alcohol: A Simple Nutrient with Complex Actions on Bone in the Adult Skeleton. Alcohol Clin Exp Res. 2016;40(4):657671. doi:10.1111/acer.13000

25. Cheraghi Z, Doosti-Irani A, Almasi-Hashiani A, et al. The effect of alcohol on osteoporosis: A systematic review and meta-analysis. Drug Alcohol Depend. 2019;197:197-202. doi:10.1016/j.drugalcdep.2019.01.025

26. Kiyota Y, Muramatsu H, Sato Y, et al. Smoking cessation increases levels of osteocalcin and uncarboxylated osteocalcin in human sera. Sci Rep. 2020;10(1). doi:10.1038/s41598-020-73789-4

27. Ji MX, Yu Q. Primary osteoporosis in postmenopausal women. Chronic Dis Transl Med. 2015;1(1):9-13. doi:10.1016/j.cdtm.2015.02.006

28. Tong X, Chen X, Zhang S, et al. The Effect of Exercise on the Prevention of Osteoporosis and Bone Angiogenesis. Biomed Res Int. 2019;2019:8171897. doi:10.1155/2019/8171897

29. Lee JH, Kim JH, Hong AR, Kim SW, Shin CS. Optimal body mass index for minimizing the risk for osteoporosis and type 2 diabetes. Korean J Intern Med. 2020;35(6):1432-1442. doi:10.3904/kjim.2018.223

30. Jiang Y, Zhang Y, Jin M, Gu Z, Pei Y, Meng P. AgedRelated Changes in Body Composition and Association between Body Composition with Bone Mass Density by Body Mass Index in Chinese Han Men over 50-year-old. PLoS One. 2015;10(6):e0130400. doi:10.1371/journal.pone.0130400

31. Abdulameer SA, Sulaiman SA, Hassali MA, Subramaniam K, Sahib MN. Osteoporosis and type 2 diabetes mellitus: what do we know, and what we can do? Patient Prefer Adherence. 2012;6:435-448. doi:10.2147/PPA.S32745

32. Jackuliak P, Payer J. Osteoporosis, fractures, and diabetes. Int J Endocrinol. 2014;2014:820615. doi:10.1155/2014/820615

33. Faienza MF, Ventura A, Marzano F, Cavallo L. Postmenopausal osteoporosis: the role of immune system cells. Clin Dev Immunol. 2013;2013:575936. doi:10.1155/2013/575936

\section{ACKNOWLEDGEMENTS}

The purchase of data from the Taiwan Biobank research database was supported by grant TMMH-107-07 from Taitung MacKay Memorial Hospital, Taitung, Taiwan.

\section{CONFLICTS OF INTEREST}

The authors have completed and submitted the ICMJE Form for Disclosure of Potential Conflicts of Interest and none was reported.

\section{FUNDING}

Funding was provided by the Taitung MacKay Memorial Hospital, Taitung, Taiwan.

\section{ETHICAL APPROVAL AND INFORMED CONSENT}

The TWB was approved by the Institutional Review Board on Biomedical Science Research/IRB-BM, Academia Sinica, Taiwan, and by the Ethics and Governance Council of the Taiwan Biobank, Taiwan. Written informed consent was obtained from each participant according to official regulations and the principles of the Declaration of Helsinki. To ensure participants' anonymity, the TWB dataset was received as deidentified data. This study protocol was approved by the Institutional Review Board at Kaohsiung Veterans General Hospital (No. KSVGH20CT10-11).

\section{DATA AVAILABILITY}

The data supporting this research is available from the authors on reasonable request.

PROVENANCE AND PEER REVIEW

Not commissioned; externally peer reviewed. 